\title{
Targeting transcriptional regulators for treatment of anaplastic thyroid cancer
}

\author{
Woo Kyung Lee, Sheue-Yann Cheng \\ Laboratory of Molecular Biology, Center for Cancer Research, National Cancer Institute, National Institutes of Health, Bethesda, \\ MD 20892, USA. \\ Correspondence to: Dr. Sheue-Yann Cheng, Chief, Gene Regulation Section, Laboratory of Molecular Biology, National Cancer \\ Institute, National Institutes of Health, 37 Convent Dr, Room 5128, Bethesda, MD 20892-4264, USA. E-mail: \\ chengs@mail.nih.gov
}

How to cite this article: Lee WK, Cheng SY. Targeting transcriptional regulators for treatment of anaplastic thyroid cancer. J Cancer Metastasis Treat 2021;7:27. https://dx.doi.org/10.20517/2394-4722.2021.58

Received: 10 Mar 2021 First Decision: 19 Apr 2021 Revised: 28 Apr 2021 Accepted: 8 May 2021 Published: 25 May 2021

Academic Editors: Jerome M. Hershman, Lucio Miele Copy Editor: Xi-Jun Chen Production Editor: Xi-Jun Chen

\begin{abstract}
Dysregulation of genes perpetuates cancer progression. During carcinogenesis, cancer cells acquire dependency of aberrant transcriptional programs (known as "transcription addiction") to meet the high demands for uncontrolled proliferation. The needs for particular transcription programs for cancer growth could be cancer-type-selective. The dependencies of certain transcription regulators could be exploited for therapeutic benefits. Anaplastic thyroid cancer (ATC) is an extremely aggressive human cancer for which new treatment modalities are urgently needed. Its resistance to conventional treatments and the lack of therapeutic options for improving survival might have been attributed to extensive genetic heterogeneity due to subsequent evolving genetic alterations and clonal selections during carcinogenesis. Despite this genetic complexity, mounting evidence has revealed a characteristic transcriptional addiction of ATC cells resulting in evolving diverse oncogenic signaling for cancer cell survival. The transcriptional addiction has presented a huge challenge for effective targeting as shown by the failure of previous targeted therapies. However, an emerging notion is that many different oncogenic signaling pathways activated by multiple upstream driver mutations might ultimately converge on the transcriptional responses, which would provide an opportunity to target transcriptional regulators for treatment of ATC. Here, we review the current understanding of how genetic alterations in cancer distorted the transcription program, leading to acquisition of transcriptional addiction. We also highlight recent findings from studies aiming to exploit the opportunity for targeting transcription regulators as potential therapeutics for ATC.
\end{abstract}


Keywords: Transcriptional addiction, transcription, oncogene addiction, cancer stem cell, thyroid hormone receptors, steroid receptor coactivators, BET inhibitor, anaplastic thyroid cancer

\section{INTRODUCTION}

A prominent hallmark of cancer is gene dysregulation, leading to initiation of tumor development, distant metastasis, and therapeutic resistance ${ }^{[1]}$. Unlike normal cells, cancer cells require high levels of active transcription to develop various survival programs and maintain uncontrolled growth ${ }^{[2]}$. The need for high transcription to propel cancer proliferation is supported by observations of over-expressed components in transcriptional machinery in diverse cancer $^{[1,3-5]}$. In particular, the development of aggressive and therapeutically recalcitrant tumors such as anaplastic thyroid cancer (ATC) is known to rely on characteristic patterns of gene expression (known as transcriptional addiction), despite a high level of genetic heterogeneity ${ }^{[0,7]}$. This transcriptional dependency requires perpetually active transcription, relying on input from transcriptional key players including chromatin regulators. Such a higher activity exhibited by transcription regulators has presented an opportunity for therapeutic intervention ${ }^{[6-10]}$.

ATC is a rare malignancy, but it is one of the most aggressive human solid cancers ${ }^{[11]}$, accounting for $1 \%-2 \%$ of all thyroid cancers, which are the most common endocrine malignancy ${ }^{[12,13]}$. ATC is extremely fastgrowing and invasive, and thus most cases present as stage IV disease with distant metastasis, making most patients ineligible for surgery ${ }^{[1,15]}$. ATC is highly resistant to conventional therapy, and the median survival of ATC patients is less than 6 months after diagnosis ${ }^{[1,1,16]}$. Currently there are no established therapeutic options to improve overall survival of these patients ${ }^{[17,18]}$. American Thyroid Association guidelines and the National Comprehensive Cancer Network Clinical Practice Guidelines for ATC recommend combination therapy including surgery, chemotherapy, and/or radiotherapy to maximize clinical benefits ${ }^{[16,19]}$. Several new tyrosine kinase inhibitors (TKIs) are currently under evaluation in phase II clinical trials for ATC. So far only a combination therapy of dabrafenib with trametinib has been approved by the United States Food and Drug Administration for BRAF-mutated ATC, which was based on the limited results from a phase II clinical trial without definite evidence of benefits on survival ${ }^{[20]}$. Therefore, development of new effective therapeutic modalities is urgently needed.

One explanation to account for the difficulties in developing effective therapeutics for ATC is the lack of well-defined driver mutations as well as clearly elucidated molecular mechanisms underlying the carcinogenesis. ATC exhibits more genetic alterations and more extensive heterogeneity than other types of thyroid cancers ${ }^{[21-23]}$. The high degree of intra- or inter-tumor heterogeneity ${ }^{[24,25]}$ presents a huge challenge in identifying effective therapeutic targets for ATC. Nevertheless, despite this genetic complexity, in a subset of ATC, a characteristic transcriptional program frequently associated with super-enhancers emerges, resulting in constitutive activation of some oncogenes ${ }^{[6,8-10,26]}$. Moreover, the expression of the oncogenes that are driven by the super-enhancers has been shown to be particularly vulnerable to the effect of transcriptional inhibitors as found in other cancers ${ }^{[27-31]}$. Thus, the molecular modulators of these transcriptional programs, especially proteins that are important for the transcriptional control, have emerged as attractive targets for aggressive cancers such as ATC. In this review, we will briefly review the transcriptional machinery process and what is known about dysregulation of transcription in cancer development. We will then discuss how the inhibitors which could disrupt transcription could impede cancer cell survival and proliferation. We will also examine the challenges to be overcome before these inhibitors could be used for therapeutics for patients. 


\section{General transcriptional machinery and its main regulators}

Transcription starts from the assembly of the pre-initiation complex (PIC), a complex of about 100 proteins that binds to the transcription start sites of genes and promotes DNA entry to the active site of RNA Polymerase II (RNA Pol II) for transcription initiation ${ }^{[32]}$ [Figure 1]. The PIC formation requires the recruitment of several general transcription factors (GTFs), which include TFIIA, TFIIB, TFIID, TFIIE, TFIIF, and TFIIH ${ }^{[33]}$. Promoters typically have a TATA box [TATA(A/T)A(A/T)(A/G)] located 25 base pairs upstream of the transcription start site ${ }^{[34]}$.

TATA binding protein (TBP), which is a subunit of TFIID, binds to the TATA box in the promoter of DNA. Subsequent recruitment of TFIIA and TFIIB stabilizes this TBP-promoter complex. TFIIB recruits RNA polymerase II and TFIIF to the promoter complex. This binding further stabilizes the RNA Pol II complex and other initiation factors on the promoter to confirm that the transcription initiation by the RNA Pol II occurs at the appropriate location ${ }^{[32,35]}$.

The mediator complex, which is a 23-subunit assembly, cooperatively binds with RNA Pol II and a subset of transcription factors (TFs) during the process of the PIC formation despite not binding directly to DNA sequence-specifically ${ }^{[36]}$. The mediator complex is recruited to promoter-enhancer regions by TFs and functions to signal the messages from the TFs to RNA Pol II, thereby enabling TF-dependent regulation of gene expression. Such communication is indispensable for transforming biological inputs from TFs to physiological responses through changes in gene expression ${ }^{[37]}$.

The final GTF to be recruited to the PIC is TFIIH, consisting of multiple subunits, including MAT1, cyclindependent kinase 7 (CDK7), its paired cyclin $\mathrm{H}$, and ATP-dependent helicases (XPB and XPD ${ }^{[38]}$. Following recruitment, XPB enables promoter opening for transcription to occur ${ }^{[39]}$, whereas CDK7mediated phosphorylation of C-terminal domain (CTD) of RPB1, which is the largest subunit of RNA Pol II, at serine 5 induces dissociation of the mediator from the PIC, thereby leading to binding of mRNA capping enzymes that catalyze addition of the methyl-guanosine cap structure to the $5{ }^{`}$ end of nascent mRNA transcript ${ }^{[40]}$. CDK7 also phosphorylates TFIIE that facilitates activities of TFIIH as an ATPase and a kinase, and its phosphorylation drives the transition from transcription initiation to elongation ${ }^{[41]}$.

Elongation of RNA Pol II pauses 30-50 nucleotides downstream of the transcription start site. This transcriptional pause enables rapid and synchronous transcriptional activation upon release of RNA Pol II from the paused state and also functions as a check point for mRNA quality control ${ }^{[42]}$. The positive transcription elongation factor $\mathrm{b}(\mathrm{P}-\mathrm{TEFb}) / \mathrm{CDK} 9$ complex is then recruited to the paused RNA Pol II and cooperates with bromodomain-containing protein $4(\mathrm{BRD} 4)$ and the super elongation complex to release RNA Pol II for active transcription. While CDK7 is important for driving the initial stages of RNA Pol II elongation, CDK9 produces a fully matured elongation complex that can engage in mRNA slicing, termination, and co-transcriptionally modifying the chromatin structure ${ }^{[43]}$. In addition, the P-TEFb promotes the CTD phosphorylation at serine 2, a conserved marker of elongating RNA Pol II in promoting recruitment of the $3^{\prime}$-end processing and splicing factors for mRNA maturation ${ }^{[4]}$. CDK12 and CDK13 also directly contribute to the CTD phosphorylation at serine 2 , transcription elongation ${ }^{[45]}$, splicing of premRNA, and transcriptional termination ${ }^{[46]}$.

\section{Mechanisms of transcriptional dysregulation in cancer}

In normal cells, cell identity is largely controlled by the action of TFs that interact with specific regions in the genome to regulate gene expression. The TFs deregulated in cancer can be subdivided into three major groups: (1) master/lineage TFs involved in organization of cell identity; (2) proliferation control TFs that can amplify transcriptional output to meet cellular demands; and (3) signaling TFs that regulate a series of 


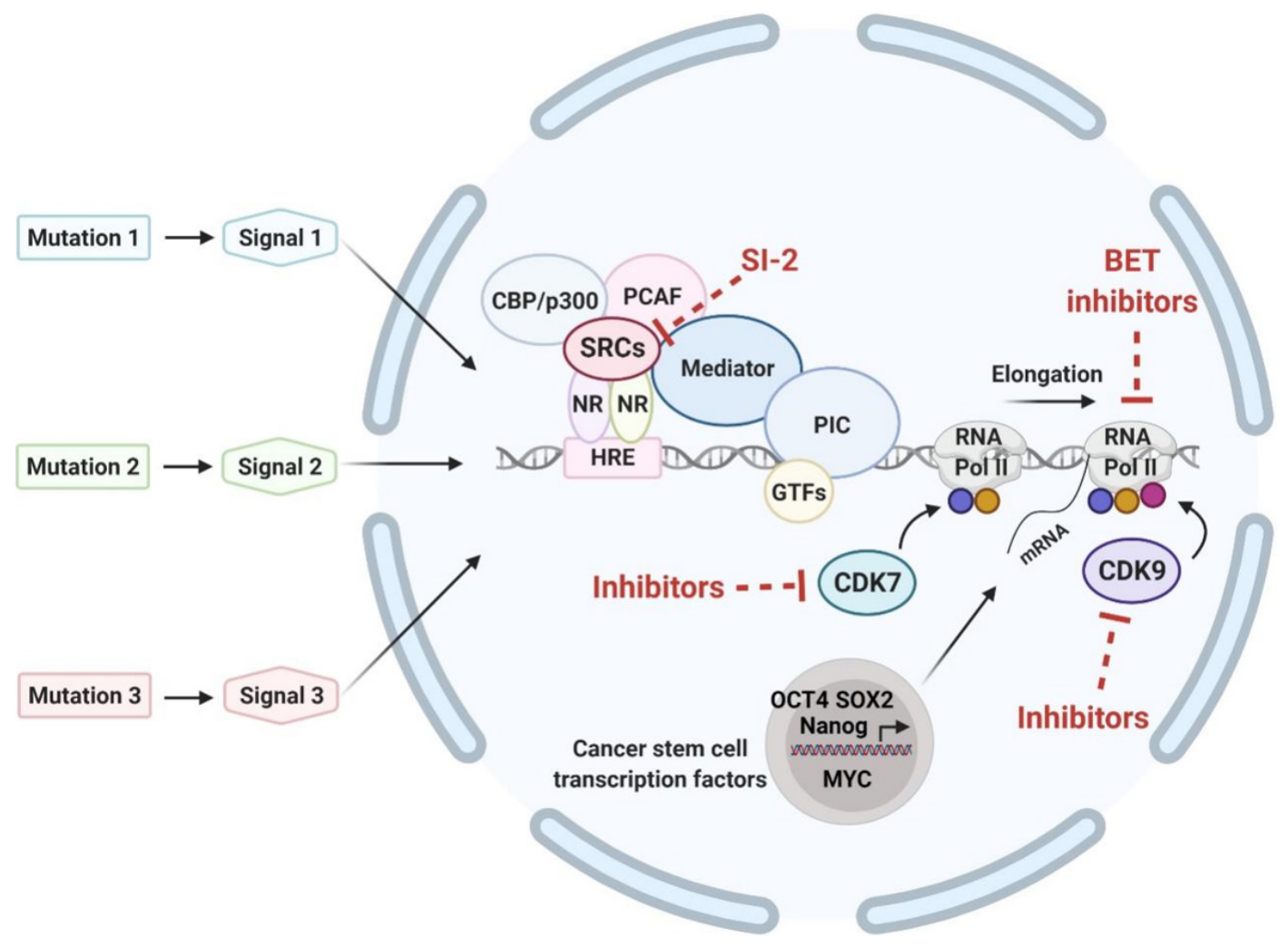

Figure 1. Converging of multiple oncogenic signals initiated from various upstream driver mutations in eliciting transcriptional responses. General transcription factors, mediators and RNA polymerase II assemble to form preinitiation complex to initiate transcription. The process of RNA elongation and termination is regulated by various cyclin-dependent kinases. Blue, yellow, and red circles indicate phosphorylation of the C-terminal domain of RNA Pol II at Ser 5, Ser 7, and Ser 2, respectively, by CDK7 or CDK9. Bromodomain and extra-terminal domain proteins (BET proteins; e.g., BRD4) interact with acetyl-lysines on the chromatin to activate transcription. Nuclear receptors bind to the hormone response element of target genes. Hormone/ligand-bound HRs recruit steroid hormone receptor coactivators (e.g., SRC-3) and other activators such as CBP/p300 and PCAF and together with mediator to form large complexes to further activate transcription. Mutational oncogenic upstream signals relay to converge on the transcription process to alter gene transcription output of proliferation- and differentiation-regulators to promote cancer progression. The expression of critical cancer stem cell transcription factors such as Oct4, Sox2, Nanog and MYC is known to be driven by super-enhancers on the chromatin. Sites in the transcription machinery that could be targeted by inhibitors are shown. NR: nuclear receptor; SRC: steroid hormone nuclear receptor coactivator; HRE: hormone response element; PCAF: CBP/p300-associated factor; PIC: pre-initiation complex; GTFs: general transcription factors; Pol II: polymerase II; CDK7: cyclin-dependent kinase 7; CDK9: cyclin-dependent kinase 9.

machineries driven by extracellular signals. Examples of master/lineage TFs are the pluripotent OCT4, SOX2, and Nanog regulators. They function to change core regulatory circuitries and induce transcriptional activation of additional genes that are normally expressed in more embryonic states. Prime examples of proliferation control TFs are MYC and TP53, the most frequently mutated genes in human cancer. Notably, MYC can have extensive effects by amplifying the entire gene expression program ${ }^{[4,4748]}$. Examples of signaling TFs are nuclear receptors including thyroid receptor (TR ${ }^{[4,50]}$ and estrogen receptor (ER), STAT3, $\beta$-catenin, and NOTCH. Dysregulated signaling TFs can significantly alter the transcriptional program by binding to enhancers occupied by master $\mathrm{TFs}^{[1,52]}$ or aberrantly promoting super-enhancer formation ${ }^{[48]}$.

Besides these TFs, several cofactors play key roles in the transcriptional process. There are two classes of cofactors: the mediator complex and chromatin regulators. Mediators act as a messenger to relay signals from the TFs to chromatin regulators such as p300/CBP, MLL1-4, BRD4, JARID1A, and SWI/SNF chromatin remodeling complex. Genetic alterations of the mediator complex are frequently observed in many cancers ${ }^{[33-55]}$. Interestingly, few cancer-associated genetic alterations in the core RNA Pol II complex 
itself have been identified, suggesting that coordinated alterations of transcriptional signals upstream of RNA Pol II are more important for the neoplastic state ${ }^{[56]}$. Chromatin regulators are important for efficient delivery of transcriptional signals from enhancers to promoters. They function globally, and thus their dysregulation can profoundly affect the gene expression program of cancer cells ${ }^{[5]}$.

Recent studies have demonstrated that specific chromosomal structures play critical roles for gene regulation. The term insulated neighborhoods was coined to indicate that genes and their regulatory elements are typically regulated together within specific DNA loop structures. These chromosomal loop structures are bound by the CTCF protein and are co-bound with the cohesin complex ${ }^{[57]}$. These chromosomal structures produce specific enhancer-gene interactions that are necessary for gene activation and repression ${ }^{[58-60]}$. Therefore, mutations of proteins in the chromosome loop structures can profoundly affect overall gene expression. According to recent cancer genome sequencing studies, somatic mutations in the CTCF protein and the cohesion complex are frequently developed in various solid tumors, and these mutations can modify the insulated neighborhoods all over the genome, thereby rendering chromatin more accessible to oncogenic transcriptional signaling for carcinogenesis ${ }^{[61,62]}$.

There are classes of cis-regulatory elements that have significant roles in cancer biology: super-enhancers and insulators that form the insulated neighborhoods. Super-enhancers are regions of the genome comprising multiple enhancers and bind to high densities of transcriptional components to drive genes involved in maintaining specific cell identities. Cancer cells attain super-enhancers for driving the expression of oncogenes through various mechanisms ${ }^{[29,63,64]}$, including DNA translocation ${ }^{[63]}$, focal amplification ${ }^{[65]}$, small insertions and deletions ${ }^{[66]}$, and epigenomic mechanisms $s^{[67]}$. Somatic mutations in loop anchors of insulated neighborhoods around oncogenes also frequently occur in diverse cancers. Of note, DNA-binding motif of the CTCF protein in loop anchor regions is one of the most frequently altered TF-binding sequences in human cancer ${ }^{[68]}$.

In addition, transcriptional dysregulations are known to be tightly linked to epigenetic alterations, contributing to pervasive gene expression changes in cancer $^{[69-71]}$. Epigenetic alterations are heritable and a dynamic process, altering the phenotypes by dysregulating gene expression without changes in DNA sequences. Epigenetic changes include DNA methylation, histone modifications, and the regulation of noncoding RNA ${ }^{[72]}$. These changes could lead to chromatin remodeling, resulting in profound changes of gene expression profiles in cancer $^{[72]}$. This epigenetic regulation allows the genome-wide transcriptional dysregulation independent of genetic change in cancer. Interestingly, the chromatin features of cell-oforigin are known to be strong predictors for cancer mutation profiles ${ }^{[73]}$, suggesting chromatin alterations as critical drivers for cancer development.

\section{Transcriptional Regulation for Maintaining Cancer Stem Cells}

For effective targeting of transcription regulators for treatment of ATC, emerging knowledge about the roles of cancer stem cells (CSCs) should be considered. The prevailing hypothesis has been that CSCs are responsible for treatment resistance and tumor relapse in aggressive cancers including ATC. CSCs are a subpopulation of cancer cells having features similar to normal embryonic stem cells (ESCs), such as selfrenewal ability and pluripotency ${ }^{[74]}$. CSCs are endowed with the ability for self-renewal and for initiating tumors at low cell density. They can also enable a considerable portion of tumor cells to be differentiated according to tumor microenvironment. CSCs are more resistant than non-CSCs to anti-cancer therapy. Such resistance enables CSCs to evolve in the clonal selection for aggressive phenotype $\mathrm{e}^{[75,76]}$. 
Numerous studies have indicated transcriptional regulation is essential for maintaining ESC status. This transcriptional regulation is mainly mediated by pluripotency TFs such as Oct4, Sox2, Nanog, and MYC. Chromatin immunoprecipitation studies revealed extensive co-binding of Oct4, Sox2, and Nanog at many active and silent genomic target regions in ESC, indicating their role in activating other pluripotency-related factors and simultaneously suppressing lineage-specific genes ${ }^{[77,78]}$. While Oct4, Sox 2 and Nanog cooperate with the mediator complex to recruit RNA Pol II for gene transcription ${ }^{[79]}$, MYC controls the transcriptional pause release of RNA Pol II through $\mathrm{p}-\mathrm{TEFb}^{[80]}$ and induces the stem cell-like state by epigenetic reprograming ${ }^{[8]}$. Interestingly, ESC-specific genes including the pluripotency TFs and their activation targets are preferentially and frequently overexpressed in poorly differentiated aggressive human cancers $^{[82-84]}$. Furthermore, this ESC-like gene signature is associated with poor clinical outcomes in those cancers, supporting existence of CSCs and their clinical significance ${ }^{[82]}$. More importantly, the genome of ESC is transcriptionally and globally hyperactive and undergoes large-scale silencing during differentiation. This transcriptional hyperactivity in ESCs is mediated by aberrant expression of the general transcriptional machinery and chromatin remodeling genes, indicating the global hyperactive transcription as a hallmark of pluripotent ESC and CSC, contributing to their plasticity ${ }^{[85-89]}$. Therefore, targeting transcriptional regulators would have clinical benefits for CSC depletion and re-differentiation in the treatment of ATC.

\section{POTENTIAL OF TRANSCRIPTIONAL REGULATORS AS BIOMARKERS AND THERAPEUTIC TARGETS IN ATC}

\section{Thyroid hormone nuclear receptors}

Thyroid hormone nuclear receptors (TRs) are members of the nuclear receptor superfamily. They are important signaling TFs to mediate biological actions of the thyroid hormone (T3) for development, growth, and metabolic homeostasis ${ }^{[50,90]}$. TRs generally act as ligand-dependent TFs by binding to thyroid hormone response elements (TREs) located in regulatory sites of their target genes ${ }^{[91]}$, but they can also control the expression of target genes that do not possess a TRE by interacting with other $\mathrm{TFs}^{[02,93]}$. Over the past decades, there have been major advances in understanding the physiological functions of TRs at the molecular level and, recently, their role in cancer biology. Previous studies have demonstrated that loss of heterozygosity, deletion, and reduced expression of the THRB gene are associated with development of diverse human cancers ${ }^{[94]}$. In addition, the THRB gene is frequently silenced through hypermethylation of its promotor region ${ }^{[95-101]}$ or via microRNA-mediated mechanisms ${ }^{[102]}$ in various cancers including thyroid cancer. These findings collectively suggest TR as a tumor suppressor. Surprisingly, a dominant-negative Cterminal frameshift mutation of TR $\beta \mathrm{PV}\left(T h r b^{P V / P V}\right.$ mice) drives tumorigenesis in thyroid ${ }^{[103]}$, mammary ${ }^{[104]}$, and pituitary ${ }^{[105]}$ gland. These deleterious effects due to the loss of functional TR $\beta$ were clearly evident in that $T R \beta^{P V /-}$ mice $^{[106]}$ and $T h r \alpha 1^{-1-} T_{h r} b^{-/-}$mice spontaneously developed metastatic follicular thyroid cancer ${ }^{[107]}$. That the loss of functional TR $\beta$ led to cancer development suggested that TRs broadly control transcriptional programs to suppress oncogenesis, raising the possibility that TR $\beta$ could be targeted for treatment of thyroid cancer.

This therapeutic potential of TR $\beta$ was tested in human differentiated thyroid cancer (DTC) cells. Evaluation of thyroid cancer specimens of patients and cancer cell lines showed that the expression of the THRB gene was suppressed through its promoter hypermethylation ${ }^{[101]}$. Further, the promoter hypermethylation level of the THRB gene was positively correlated with thyroid cancer progression. When human thyroid cancer cell lines in which the THRB gene was silenced through its promoter hypermethylation were treated with demethylation agents, the THRB gene expression was reactivated, which suppressed cancer cell proliferation and migration, and in vivo tumor growth in a xenograft model. These actions of the reactivated THRB gene occurred through suppression of the $\beta$-catenin signaling pathway in thyroid cancer cell lines ${ }^{[101]}$. These findings led to the direct demonstration that the exogenous expression of the THRB gene could suppress 
tumor cell proliferation and growth ${ }^{[100]}$. Indeed, exogenous expression of THRB in human follicular thyroid cancer (FTC) cells (FTC-133 and FTC-236) reduced cell proliferation and impaired cell migration through inhibition of the PI3K-AKT-mTOR pathway. Further, in xenograft tumors, the re-expressed THRB inhibited tumor growth and angiogenesis through suppression of vascular endothelial growth factor (VEGF) signaling pathway ${ }^{[100]}$. In these studies, how TR $\beta$ acted to converge these upstream signals to the nuclear transcription was not clear. The elucidation of the underlying mechanisms awaits further in-depth analysis. Nonetheless, these findings hold high promise that TR $\beta$ could be a potential therapeutic target for thyroid cancer.

\section{MYC and bromodomain and extra-terminal domain proteins}

MYC is a master regulator of many fundamental processes such as cell cycle entry and progression, ribosome biogenesis, and metabolism. In cancer, the MYC transcriptional network is frequently overactivated through various mechanisms such as gene duplications, somatic mutations and chromosomal translocations, which increase MYC stability, thereby allowing tumor initiation and progression. MYC is overexpressed in more than half of all tumors and therefore has been regarded as one of the most important oncogenes in cancer ${ }^{[108]}$.

Uncontrolled expression of the MYC gene has been known to be responsible for the development and progression of $\mathrm{ATC}^{[109,110]}$. MYC protein is frequently upregulated in ATC tumor tissues ${ }^{[10]}$, and its high expression has been associated with poor clinical outcome ${ }^{[111,112]}$. In a mouse model of ATC, high expression of the $M Y C$ gene was related to thyroid cancer progression as indicated by the loss of differentiation ${ }^{[113]}$. In a mouse model of lung cancer, systemic inhibition of the MYC gene using a dominant negative MYC mutant resulted in complete eradication of the lung cancers ${ }^{[114]}$. However, so far, there has been no effective approach to directly controlling the functions of the MYC protein itself.

Chromatin remodeling through histone acetylation plays a crucial role for the transcriptional control ${ }^{[115]}$. The bromodomain and extra-terminal domain (BET) family of proteins, such as bromodomain-containing protein 4 (BRD4), interacts with the acetylated histones to recruit transcription activators and co-activators, and chromatin complexes to particular promoter regions ${ }^{[116]}$. Small-molecule inhibitors such as JQ1 selectively targeting this interaction between BET proteins and acetylated histones have been shown to potently inhibit the MYC-mediated transcriptional program by attenuating super-enhancers in diverse cancers $^{[117-122]}$.

In thyroid cancer, JQ1 decreased MYC expression, induced cell cycle arrest, and suppressed tumor growth in a xenograft mouse model ${ }^{[123,124]}$. In a preclinical mouse model of ATC $\left(\operatorname{Thrb}^{P V / P V} \operatorname{Kras}^{G 12 D}\right)^{[125]}$, JQ1 was found to effectively suppress $M Y C$ expression and attenuate MYC-mediated transcriptional programs, thereby inhibiting tumor growth and finally prolonging mice survival ${ }^{[125]}$. The efficacy of JQ 1 was further tested in four cell lines originated from human ATC patients ${ }^{[110]}$. JQ1 markedly inhibited tumor cell proliferation through Go/G1 cell cycle arrest by suppressing $M Y C$ and inducing p21, p27, and RB dephosphorylation. JQ1 also could impair cancer cell invasion through attenuation of epithelialmesenchymal transition (EMT) program. These in vitro findings were further confirmed by xenograft studies showing that JQ1 inhibited the size and growth rate of tumor by suppressing p21-Cyclins/CDKs-RbE2F signaling axis ${ }^{[110]}$. All these findings collectively suggested that epigenetic action of JQ1 blocking the interaction of $\mathrm{BRD} 4$ with histone acetyl-lysine sites across chromatin could suppress MYC transcription, thereby interrupting ATC progression. 
Despite JQ1's effective inhibition of tumor growth via suppression of MYC transcription, it showed no apparent inhibitory effects on tumor invasion and metastasis. This suggested that there were other oncogenic events to drive invasion and metastasis for the ATC progression. The MAPK-MEK signaling pathway is frequently upregulated in human ATC and is related to the ATC progression ${ }^{[126-128]}$. An MEK inhibitor, trametinib, was therefore used as a combined treatment with JQ1 to test this hypothesis in two human ATC cells, THJ-11T and $-16 \mathrm{~T}^{[129]}$. Remarkably, although either JQ1 alone or trametinib alone showed only partial effects, the combined treatment totally blocked proliferation of the ATC cells. Combined treatment downregulated MYC expression much more than each single treatment did, leading to suppression of pro-survival regulators and induction of pro-apoptotic regulators to cooperatively induce apoptosis. In xenograft studies, while each single treatment only partially inhibited growth of either THJ$11 \mathrm{~T}$ or $-16 \mathrm{~T}$-induced tumors, the combined treatment near completely $(>90 \%)$ blocked the tumor growth. This dramatic inhibition of tumor growth by the combined treatment occurred through synergistic suppression of $M Y C$, which induced apoptotic regulators thereby markedly promoting tumor apoptosis. The underlying mechanism that the combined treatment synergistically suppressed MYC expression was further studied. Chromatin immunoprecipitation (ChIP) assay was used to probe the effects of JQ1 and trametinib on the binding of BRD4 to the MYC promoter in THJ-11T and -16T cells. As shown in Figure 2, JQ1, trametinib, and the combined treatment inhibited the BRD4 binding to the MYC promoter by $55 \%$, $42 \%$, and $69 \%$, respectively, compared to the control (vehicle-treated cells), in THJ-11T cells [Figure $2 \mathrm{C}-\mathrm{i}$ ]. Similar efficacy profiles of the three treatments in the BRD4 binding suppression were observed in THJ-16T cells $(46 \%, 36 \%$, and $64 \%$ by JQ1, trametinib, and the combined treatment, respectively, Figure $2 \mathrm{C}$-ii). These data indicated that JQ1 and trametinib functioned, at least in part, to inhibit the BRD4 binding to histone acetyl-lysine sites across the chromatin. Further, these two inhibitors could synergistically suppress MYC transcription via cooperative actions on chromatic modifications [Figure $2 \mathrm{~A}$ and $\mathrm{B}$ ].

The efficacy of combined treatment with BET and MEK inhibitors was further demonstrated by using the second generation of a BET inhibitor. A new BET inhibitor PLX51107 (PLX) has demonstrated more favorable pharmacokinetic profiles than JQ1 and other BET inhibitors ${ }^{[130]}$. It has been under clinical trials for various solid tumors and hematological malignancies. PD0325901 (PD) is a MEK inhibitor that has also been evaluated in clinical trials for several cancers ${ }^{[131]}$. PLX and PD individually could suppress proliferation of both THJ-11T and -16T cells, but together exhibited synergistic inhibition. In mouse xenografts derived from the ATC cells, the combined treatment nearly completely blocked in vivo tumor growth. PD effectively reduced MEK-ERK signaling, and this inhibition was further augmented by the combined treatment with PLX in the ATC cells and tumors. Notably, PLX and PD synergistically attenuate MYC transcription to induce p27 for the tumor suppression. They also cooperated to activate pro-apoptotic regulators to induce apoptosis. These data indicated cooperation of PLX and PD that block BRD4 binding to histone acetyllysine sites on the promoter of the MYC gene. These collaborative actions could converge to induce epigenetic modifications to suppress MYC transcription. The efficacy of combined treatment was clearly demonstrated by using two different sets of BET and MEK inhibitors. These findings clearly demonstrated that epigenetic modifications on chromatin is a viable and effective approach for the treatment of ATC.

\section{Steroid hormone nuclear receptor coactivators}

The steroid hormone nuclear receptor coactivators (SRCs: SRC-1, SRC-2, and SRC-3) are important transcriptional coactivators discovered initially for the regulation of the transcriptional activity of the nuclear receptor superfamily. Subsequently, other transcription factors - including STATs, P53, RB, E2F1,

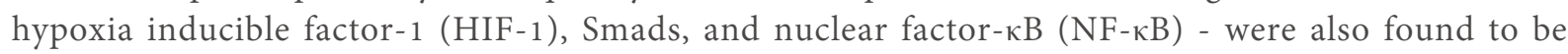
modulated by SRCs ${ }^{[132]}$. Upon ligand (hormone) binding, the ligand-bound nuclear receptors (NRs) open their coactivator-binding motifs in their ligand-binding domains and recruit SRCs to the enhancer sites of NR-target genes. SRCs further recruit other common transcriptional coactivators such as CBP/p300 and 
A
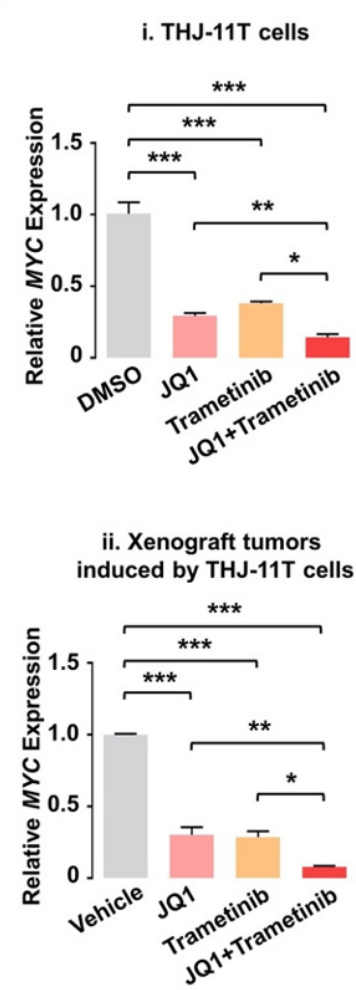

B
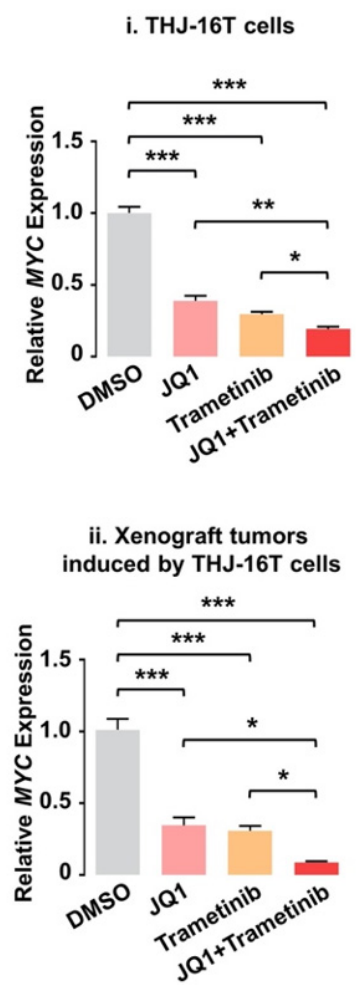

C
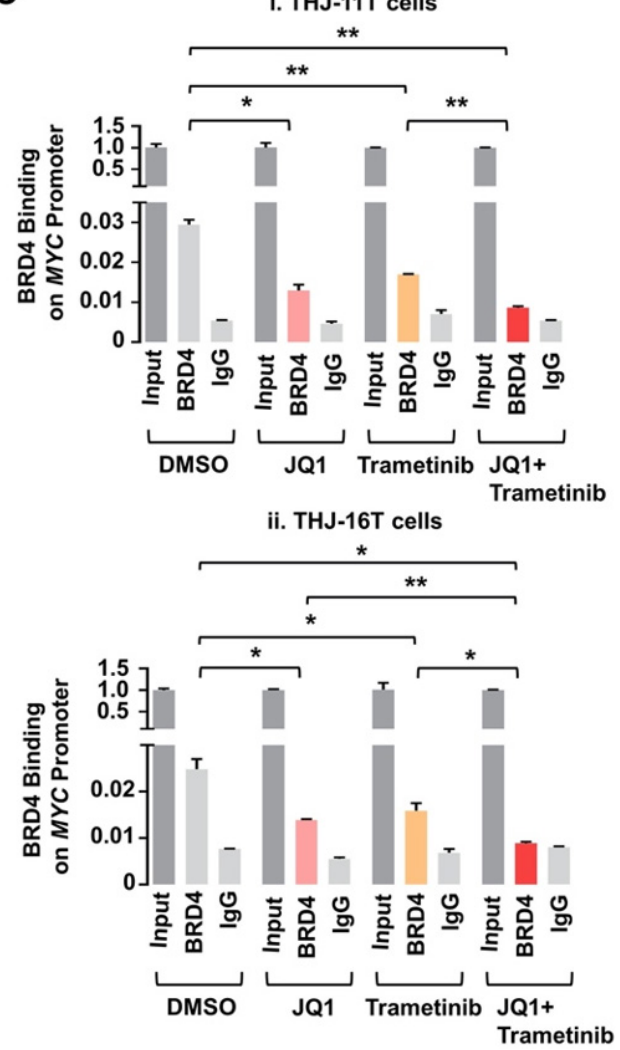

Figure 2. JQ1 and trametinib synergistically decrease mRNA expression of the MYC gene by attenuating recruitment of BRD4 to the MYC promoter in ATC cells and tumors. (A, B) The mRNA levels of the MYC gene in THJ-11T cells (A-i), -16T cells (B-i), and -11T (A-ii) and -16T xenograft tumors (B-ii). (C) Chromatin immunoprecipitation assays show BRD4 binding on the MYC promoter in THJ-11T (i) and $-16 \mathrm{~T}$ cells (ii). Significant differences were indicated by asterisks $\left({ }^{\star} P<0.05,{ }^{\star \star} P<0.01 \text {, and }{ }^{\star \star \star} P<0.001\right)^{[129]}$. (Permission from the authors).

$\mathrm{CBP} / \mathrm{p} 300$-associated factor (PCAF), coactivator-associated arginine methyltransferase 1 (CARM1), and protein arginine N-methyltransferase 1 (PRMT1) to the chromatin to form a NR-driven transcriptional activation complex. This protein complex uses its acetyltransferase and methyltransferase activities for chromatin remodeling to facilitate the assembly of the GTFs and RNA Pol II on the promoter for the transcriptional activation ${ }^{[133-138]}$ [Figure 1].

Among the SRCs, SRC-3 is the most well-studied in cancer biology. SRC-3 was initially identified as a transcriptional coactivator amplified in estrogen receptor (ER)-positive breast and ovarian cancer ${ }^{[139]}$. Its amplification and/or overexpression were subsequently found in diverse hormone-independent as well as dependent cancers ${ }^{[140,141]}$, supporting its role for transcriptional activation of oncogenes. Supporting this notion, mice overexpressing SRC-3 developed malignant breast, pituitary, and uterine tumors through activation of the PI3K/AKT and insulin growth factor 1 (IGF-1) signaling pathway ${ }^{[142]}$. As mentioned in the earlier sections of this review, we generated a knock-in mutant mouse harboring a dominant negative mutant thyroid hormone receptor $\beta$ mutant ( $T h r b^{P V / P V}$ mice). Thr $b^{P V / P V}$ mice spontaneously develop aggressive FTC ${ }^{[103]}$. Interestingly, Thrb ${ }^{P V / P V}$ mice deficient in SRC-3 $\left(\mathrm{Thrb}^{P V / P V} \mathrm{Src}_{-3^{-/}}\right)$exhibit impeded thyroid cancer growth, progression and distant metastasis with a significantly increased survival, compared to $T h r b^{P V / P V}$ mice with normal SRC-3 function $\left(T h r b^{P V / P V} S r c-3^{+/+}\right)^{[143]}$. These findings suggest SRC-3 as an oncogene and thus a potential therapeutic target in thyroid cancer. 
Although transcriptional coactivators are difficult to target because of their large size and disordered structures ${ }^{[144]}$, a new generation SRC-3 inhibitor-2 (SI-2) was developed through cellular function-based high-throughput screening. SI-2 selectively targeted breast cancer cells through inhibition of SRC-3 transcriptional activities ${ }^{[145]}$. On the basis of known complex transcriptional oncogenic changes observed in $\mathrm{ATC}^{[2,2,23,146]}$ and the critical role of SRC-3 for transcriptional regulation, the expression of SRC-3 was examined during human thyroid cancer progression from normal, through DTC (FTC and PTC), to $\mathrm{ATC}^{[147]}$. Comparison of the SRC-3 protein abundance among human normal thyroid tissue [Figure $\left.3 \mathrm{~A}-\mathrm{I}-\mathrm{a}\right]$, FTC [Figure 3A-I-b], papillary thyroid cancer (PTC) [Figure 3A-I-c], and ATC [Figure 3A-I-d-f] shows that SRC-3 is clearly higher in ATCs than in normal thyroid tissues, FTC, and PTC [Figure 3A-II]. Quantitative analysis shows that $54.6 \%$ of ATC cells were positive for SRC-3 vs. only $18.6 \%$ of PTC cells, $13.9 \%$ of FTC cells, and $18.3 \%$ of normal thyroid cells [Figure 3A-III]. Of note, further investigation for co-expression of SRC-3 and Ki-67 (a proliferation marker), clearly demonstrated a strong positive correlation $(r=0.8447, P<$ 0.0001 ) between SRC-3 and Ki-67 expression in human ATC tissues, suggesting that hyperactive transcriptional responses through aberrant expression of SRC-3 are responsible for uncontrolled proliferation of human ATC [Figure 3B-IandII].

The fact that SRC-3 was both highly elevated and associated with increased proliferation provided the basis to test the efficacy of SI-2 in the treatment of ATC ${ }^{[147]}$. SI-2 treatment of cultured human ATC cell lines (THJ-11T and -16T) markedly suppressed tumor cell proliferation by inducing apoptosis and impeding cell cycle progression. Remarkably, growth of tumors derived from THJ-11T [Figure 4A-I] or -16 T [Figure 4AII] cells was inhibited by SI- 2 . The mean tumor weight was reduced by $76 \%$ and $70 \%$, respectively, in the SI2 -treated group, compared to the vehicle-treated control group [Figure 4B-I and -II]. The inhibition of tumor growth by SI-2 was due to induction of apoptosis as evidenced by the detection of high levels of cleaved caspase 3 and pro-apoptotic regulators such as Bim in the xenograft tumors. In addition, proliferation of tumor cells was reduced as evidenced by reduced levels of Ki-67 and cyclin D1. Moreover, SI-2 blocked the activity of CSCs through inhibition of aldehyde dehydrogenase activity and expression. This observation suggested that a global transcriptional program through SRC-3 is critical for maintaining CSCs in ATC.

Finally, in-depth gene set enrichment analysis (GSEA) using The Cancer Genome Atlas Program-Thyroid Cancer (TCGA-THCA) data confirmed extensive involvement of SRC-3 in the activation of multiple oncogenic signaling pathways. The coordinated activation of 48 cancer-driver genes through SRC-3 signals poor clinical outcome in human thyroid cancer. The GSEA further indicated that this involvement of SRC-3 occurred through enrichment of genetic regions occupied by oncogenic transcription factors such as the MYC/MAX complex, NF- $\mathrm{kB}, \mathrm{E} 2 \mathrm{~F} 1$, and $\mathrm{ETS}_{1}{ }^{[147]}$. These findings suggest that many different oncogenic signaling pathways driven by multiple upstream driver mutations assembled on the transcription responses. SRC-3 would have a critical role in the final manifestation of oncogenic transcription responses, and therefore the identification of small-molecule inhibitors such as SI-2 to target SRC-3 is a promising strategy for effective ATC treatment.

\section{Transcription-associated cyclin-dependent kinases}

The cyclin-dependent kinases (CDKs) are the families of serine/threonine kinases that mediate fundamental cellular processes such as cell proliferation and survival. They can generally be classified into two major groups: cell cycle-related CDKs (CDK1, CDK2, CDK4, and CDK6) and transcription-associated CDKs (CDK7, CDK8, CDK9, CDK12, and CDK13). Each CDK is bound to a specific cyclin partner that guides the CDK activity. Because of their important role in cancer cell survival and growth, they have been regarded as promising therapeutic targets. Recently, CDK4/6 inhibitors have been shown to be effective in preclinical studies of multiple cancer types ${ }^{[148-150]}$, and impressive clinical outcomes have been demonstrated in 
A-I

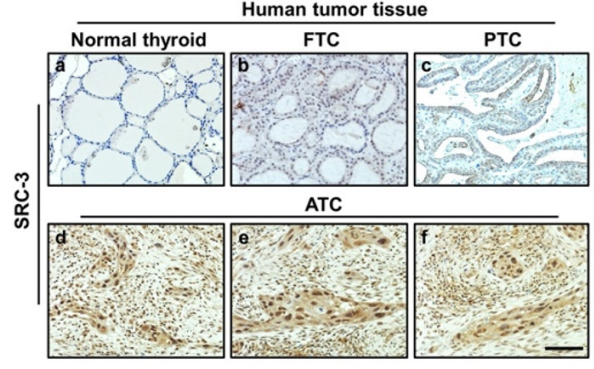

A-II

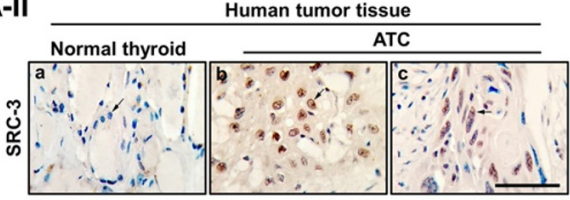

B-I

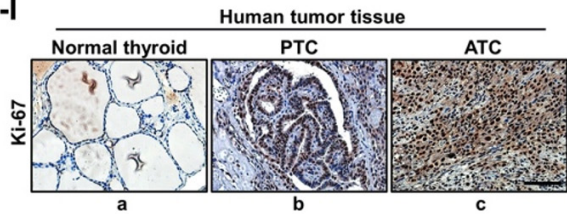

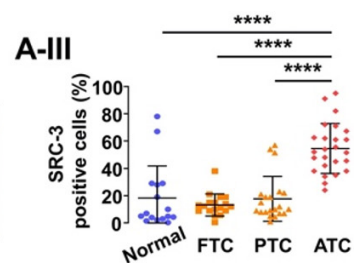

B-II

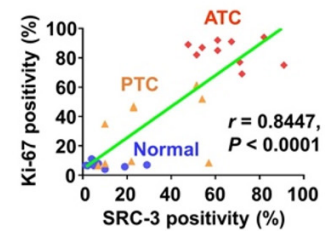

Figure 3. Elevated expression of SRC-3 in human ATC. (A) Immunohistochemistry (IHC) images for SRC-3 (I), their magnified images ( $\times 2$ ) showing nuclear staining of SRC-3 (II), and quantitative analysis for the IHC results (III) in different stages of human thyroid cancer. (B) IHC images for Ki-67 (I) in normal thyroid, PTC, and ATC, and correlation plot showing strong positive relationship between SRC-3 and Ki-67 expression in ATC (II). Significant differences were indicated by asterisks ( $\left.{ }^{\star \star \star \star} P<0.0001\right)$. Scale bars represent $50 \mu$ m. ATC: Anaplastic thyroid cancer; FTC: follicular thyroid cancer; PTC: papillary thyroid cancer ${ }^{[147]}$. (Permission from the authors).

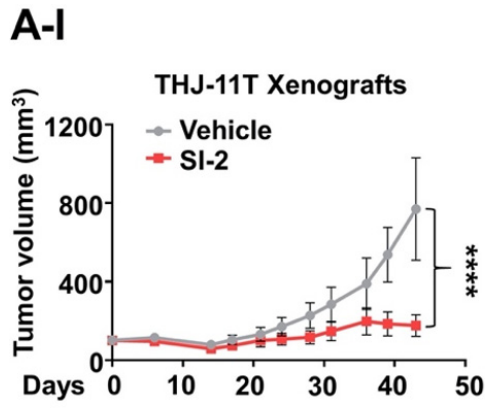

B-I

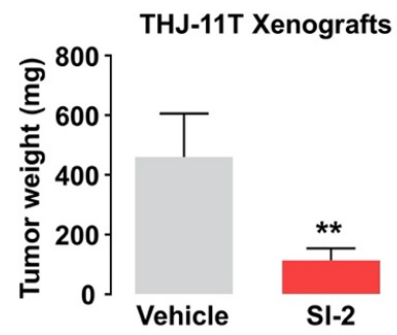

A-II

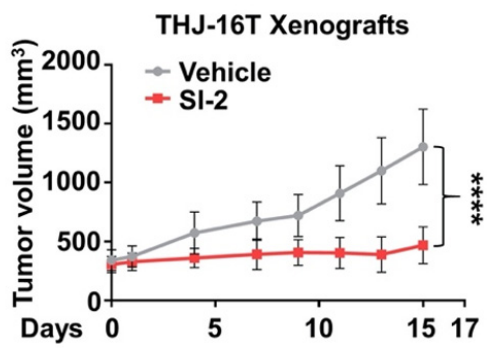

B-II

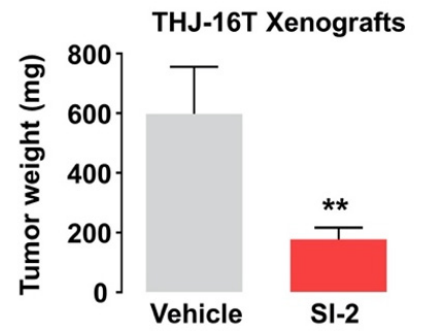

Figure 4. Therapeutic efficacy of SI-2 in ATC xenograft mice models. (A, B) Growth curves (A) and weight (B) of THJ-11T (I) and -16T (II) xenograft tumors treated with vehicle or SI-2. Significant differences are indicated by asterisks $\left({ }^{\star \star} P<0.01\right.$ and $\left.{ }^{\star \star \star \star} P<0.0001\right)$. Data represent the mean $\pm \mathrm{SD}^{[147]}$.

hormone-positive breast cancer ${ }^{[151,152]}$. Development of small-molecule inhibitors targeting the transcriptionassociated CDKs has been slow, and few have entered into clinical use. Still, growing numbers of studies have shown strong efficacy of these inhibitors, particularly in a subset of cancers that exhibit the transcriptional addiction, including small cell lung cancer ${ }^{[10]}$, ovarian cancer ${ }^{[8]}$, and triple-negative breast cancer $^{[6]}$, and T-cell acute lymphoblastic leukemia ${ }^{[9]}$ [Figure 1]. 
The efficacy of targeting the transcription-associated CDKs has also been shown in aggressive medullary thyroid cancer (MTC) and ATC. The development and progression of MTC are known to be driven by the gain of function mutations of the RET proto-oncogene. A super-enhancer in the intron 1 of the RET gene provides the sensitivity to be targeted by CDK9 inhibitors alone or with a RET kinase inhibitor ${ }^{[153]}$. ATC cells that exhibit super-enhancers-mediated transcription addiction were shown to be sensitive to transcription inhibition by the $\mathrm{CDK}^{[26]}$ or $\mathrm{CDK} 12$ inhibitor ${ }^{[154]}$. However, intriguingly, MYC was not found in the list of the super-enhancer-mediated or $\mathrm{THZ}_{1}$ (CDK7 inhibitor)-sensitive cancer genes in these studies. Of note, previous findings reported that ATC cells heavily rely on MYC-driven transcriptional addiction $^{[110,125,155]}$ and that the CDK7 inhibitor led to massive suppression of MYC-driven global transcriptional amplification ${ }^{[8,10,156]}$. One possible explanation for these differences among studies could be the use of different experimental models. Therefore, it would be important to develop additional experimental models that could be comprehensively analyzed and validated. Furthermore, in view of the importance of CSCs in chemoresistance and recurrence of ATC, the potential effects of inhibitors targeting the transcription-associated CDKs on CSC activity should be evaluated and its underlying molecular mechanisms elucidated. The fruitful outcome of such studies will broaden the availability of urgently needed therapeutic targets for ATC.

\section{CONCLUSION AND FUTURE PERSPECTIVES}

ATC's complex and heterogeneous genetic profiles with high transcriptional output enable continuous development of survival programs in the face of current targeted therapies. Early studies showed multiple upstream driver mutations to initiate carcinogenesis. More recent studies indicated that such driver mutations initiated upstream could converge to trigger transcriptional responses as evidenced by global genomic analyses. Mutations in transcriptional regulators such as components of SWI/SNF chromatin remodeling complex, histone methyltransferases, and EIF1AX (a key component of the translational preinitiation complex) were identified in $\mathrm{ATC}^{[22,23,146]}$, supporting the potential of transcriptional regulators as therapeutic targets for ATC treatment.

Indeed, as presented in this review, our studies have provided the rationale for potential clinical trials using small-molecule inhibitors such as JQ1 (BET inhibitor), PLX51107 (BET inhibitor), and SI-2 (SRC-3 inhibitor) to target the transcriptional regulators in ATC patients. Targeting other key components of the transcriptional machinery, such as chromatin regulators, the mediator, and other transcriptional coactivators, would also have profound effects on the final manifestation of oncogenic transcriptional responses. Thus, the identification of small-molecule inhibitors targeting them (or activators for TRs) is a promising strategy for effective ATC treatment.

Several important questions require further investigations to bridge the gap between preclinical studies and clinical application. Therapeutic windows for each inhibitor would have to be assessed in clinical trials because the transcriptional inhibition can affect normal as well as cancer cells. Defining the therapeutic windows for selectively targeting the cancer transcription program could avoid side effects thereby enhancing the well-being of the patients. Further, identification of transcription inhibitors which could deplete CSCs in ATC could minimize chemoresistance and recurrence. The elucidation of how the key players regulating the transcription programs lead to depleting of CSCs would certainly expand the choice of therapeutic targets for ATC to further benefit patients.

\section{DECLARATIONS}

\section{Acknowledgments}

We wish to thank all our colleagues and collaborators who have contributed to the work presented in this 
review. We regret not being able to cite the work published by many others due to the limitation of length. Graphics programs available from BioRender.com were used by the authors to design and create Figure 1.

\section{Authors' contributions}

Conception and design: Lee WK, Cheng SY

Writing, review, and revision: Lee WK, Cheng SY

\section{Availability of data and materials}

No applicable.

\section{Financial support and sponsorship}

Our research was supported by the Intramural Research Program of the Center for Cancer Research, National Cancer Institute, National Institutes of Health (ZIA BC 011191).

\section{Conflicts of interest}

Both authors declared that there are no conflicts of interest.

\section{Ethical approval and consent to participate}

Not applicable.

\section{Consent for publication}

Not applicable.

\section{Copyright}

(c)The Author(s) 2021.

\section{REFERENCES}

1. Bradner JE, Hnisz D, Young RA. Transcriptional addiction in cancer. Cell 2017;168:629-43. DOI PubMed PMC

2. Franco HL, Kraus WL. No driver behind the wheel? Cell 2015;163:28-30. DOI PubMed

3. Adhikary S, Eilers M. Transcriptional regulation and transformation by Myc proteins. Nat Rev Mol Cell Biol 2005;6:635-45. DOI PubMed

4. Lin CY, Lovén J, Rahl PB, et al. Transcriptional Amplification in tumor cells with elevated c-Myc. Cell 2012;151:56-67. DOI PubMed PMC

5. Luo Z, Lin C, Guest E, et al. The super elongation complex family of RNA polymerase II elongation factors: gene target specificity and transcriptional output. Mol Cell Biol 2012;32:2608-17. DOI PubMed PMC

6. Wang Y, Zhang T, Kwiatkowski N, et al. CDK7-dependent transcriptional addiction in triple-negative breast cancer. Cell 2015;163:174-86. DOI PubMed PMC

7. Zanconato F, Battilana G, Forcato M, et al. Transcriptional addiction in cancer cells is mediated by YAP/TAZ through BRD4. Nat Med 2018;24:1599-610. DOI PubMed PMC

8. Zeng M, Kwiatkowski NP, Zhang T, et al. Targeting MYC dependency in ovarian cancer through inhibition of CDK7 and CDK12/13. Elife 2018;7:e39030. DOI PubMed PMC

9. Kwiatkowski N, Zhang T, Rahl PB, et al. Targeting transcription regulation in cancer with a covalent CDK7 inhibitor. Nature 2014;511:616-20. DOI PubMed PMC

10. Christensen CL, Kwiatkowski N, Abraham BJ, et al. Targeting transcriptional addictions in small cell lung cancer with a covalent CDK7 inhibitor. Cancer cell 2014;26:909-22. DOI PubMed PMC

11. Molinaro E, Romei C, Biagini A, et al. Anaplastic thyroid carcinoma: from clinicopathology to genetics and advanced therapies. Nat Rev Endocrinol 2017;13:644-60. DOI PubMed

12. Lee WK, Lee J, Kim H, et al. Peripheral location and infiltrative margin predict invasive features of papillary thyroid microcarcinoma. Eur J Endocrinol 2019;181:139-49. DOI PubMed

13. Choi JB, Lee WK, Lee SG, et al. Long-term oncologic outcomes of papillary thyroid microcarcinoma according to the presence of clinically apparent lymph node metastasis: a large retrospective analysis of 5,348 patients. Cancer Manag Res 2018;10:2883-91. DOI PubMed PMC

14. Tuttle RM, Haugen B, Perrier ND. Updated American Joint Committee on cancer/tumor-node-metastasis staging system for differentiated and anaplastic thyroid cancer: what changed and why? Thyroid 2017;27:751-6. DOI PubMed PMC

15. Ferrari SM, Elia G, Ragusa F, et al. Novel treatments for anaplastic thyroid carcinoma. Gland Surg 2020;9:S28-42. DOI PubMed PMC

16. Smallridge RC, Ain KB, Asa SL, et al. American Thyroid Association guidelines for management of patients with anaplastic thyroid cancer. Thyroid 2012;22:1104-39. DOI PubMed 
17. Tiedje V, Stuschke M, Weber F, Dralle H, Moss L, Fuhrer D. Anaplastic thyroid carcinoma: review of treatment protocols. Endocr Relat Cancer 2018;25:R153-61. DOI PubMed

18. Smallridge RC. Approach to the patient with anaplastic thyroid carcinoma. J Clin Endocrinol Metab 2012;97:2566-72. DOI PubMed PMC

19. Haddad RI, Lydiatt WM, Ball DW, et al. Anaplastic thyroid carcinoma, version 2.2015. J Natl Compr Canc Netw 2015;13:1140-50. DOI PubMed PMC

20. Subbiah V, Kreitman RJ, Wainberg ZA, et al. Dabrafenib and trametinib treatment in patients with locally advanced or metastatic BRAF V600-mutant anaplastic thyroid cancer. J Clin Oncol 2018;36:7-13. DOI PubMed PMC

21. Kunstman JW, Juhlin CC, Goh G, et al. Characterization of the mutational landscape of anaplastic thyroid cancer via whole-exome sequencing. Hum Mol Genet 2015;24:2318-29. DOI PubMed PMC

22. Pozdeyev N, Gay LM, Sokol ES, et al. Genetic analysis of 779 advanced differentiated and anaplastic thyroid cancers. Clin Cancer Res 2018;24:3059-68. DOI PubMed PMC

23. Yoo SK, Song YS, Lee EK, et al. Integrative analysis of genomic and transcriptomic characteristics associated with progression of aggressive thyroid cancer. Nat Commun 2019;10:1-12. DOI PubMed PMC

24. Lee WK, Lee SG, Yim SH, et al. Whole exome sequencing identifies a novel hedgehog-interacting protein g516r mutation in locally advanced papillary thyroid cancer. Int J Mol Sci 2018;19:2867. DOI PubMed PMC

25. Le Pennec S, Konopka T, Gacquer D, et al. Intratumor heterogeneity and clonal evolution in an aggressive papillary thyroid cancer and matched metastases. Endocr Relat Cancer 2015;22:205-16. DOI PubMed

26. Cao X, Dang L, Zheng X, et al. Targeting super-enhancer-driven oncogenic transcription by CDK7 inhibition in anaplastic thyroid carcinoma. Thyroid 2019;29:809-23. DOI PubMed

27. Whyte WA, Orlando DA, Hnisz D, et al. Master transcription factors and mediator establish super-enhancers at key cell identity genes. Cell 2013;153:307-19. DOI PubMed PMC

28. Lovén J, Hoke HA, Lin CY, et al. Selective inhibition of tumor oncogenes by disruption of super-enhancers. Cell 2013;153:320-34. DOI PubMed PMC

29. Chapuy B, McKeown MR, Lin CY, et al. Discovery and characterization of super-enhancer-associated dependencies in diffuse large B cell lymphoma. Cancer cell 2013;24:777-90. DOI PubMed PMC

30. Hnisz D, Abraham BJ, Lee TI, et al. Super-enhancers in the control of cell identity and disease. Cell 2013;155:934-47. DOI PubMed PMC

31. Shi J, Whyte WA, Zepeda-Mendoza CJ, et al. Role of SWI/SNF in acute leukemia maintenance and enhancer-mediated Myc regulation. Genes Dev 2013;27:2648-62. DOI PubMed PMC

32. Sainsbury S, Bernecky C, Cramer P. Structural basis of transcription initiation by RNA polymerase II. Nat Rev Mol Cell Biol 2015;16:129-43. DOI PubMed

33. Asturias FJ. RNA polymerase II structure, and organization of the preinitiation complex. Curr Opin Struct Biol 2004;14:121-9. DOI PubMed

34. Warfield L, Ramachandran S, Baptista T, Devys D, Tora L, Hahn S. Transcription of nearly all yeast RNA polymerase II-transcribed genes is dependent on transcription factor TFIID. Mol Cell 2017;68:118-29.e5. DOI PubMed PMC

35. Thomas MC, Chiang C-M. The general transcription machinery and general cofactors. Crit Rev Biochem Mol Biol 2006;41:105-78. DOI PubMed

36. Mittler G, Kremmer E, Timmers HTM, Meisterernst M. Novel critical role of a human Mediator complex for basal RNA polymerase II transcription. EMBO Rep 2001;2:808-13. DOI PubMed PMC

37. Poss ZC, Ebmeier CC, Taatjes DJ. The Mediator complex and transcription regulation. Crit Rev Biochem Mol Biol 2013;48:575-608. DOI PubMed PMC

38. Compe E, Egly J-M. TFIIH: when transcription met DNA repair. Nat Rev Mol Cell Biol 2012;13:343-54. DOI PubMed

39. Moreland RJ, Tirode F, Yan Q, Conaway JW, Egly J-M, Conaway RC. A role for the TFIIH XPB DNA helicase in promoter escape by RNA polymerase II. J Biol Chem 1999;274:22127-30. DOI PubMed

40. Ghosh A, Shuman S, Lima CD. Structural insights to how mammalian capping enzyme reads the CTD code. Mol Cell 2011;43:299310. DOI PubMed PMC

41. Larochelle S, Amat R, Glover-Cutter K, et al. Cyclin-dependent kinase control of the initiation-to-elongation switch of RNA polymerase II. Nat Struct Mol Biol 2012;19:1108-15. DOI PubMed PMC

42. Jonkers I, Lis JT. Getting up to speed with transcription elongation by RNA polymerase II. Nat Rev Mol Cell Biol 2015;16:167-77. DOI PubMed PMC

43. Marshall NF, Price DH. Purification of P-TEFb, a transcription factor required for the transition into productive elongation. $J$ Biol Chem 1995;270:12335-8. DOI PubMed

44. Hsin JP, Manley JL. The RNA polymerase II CTD coordinates transcription and RNA processing. Genes Dev 2012;26:2119-37. DOI PubMed PMC

45. Fan Z, Devlin JR, Hogg SJ, et al. CDK13 cooperates with CDK12 to control global RNA polymerase II processivity. Sci Adv 2020;6:eaaz5041. DOI PubMed PMC

46. Liang K, Gao X, Gilmore JM, et al. Characterization of human cyclin-dependent kinase 12 (CDK12) and CDK13 complexes in Cterminal domain phosphorylation, gene transcription, and RNA processing. Mol Cell Biol 2015;35:928-38. DOI PubMed PMC

47. Nie Z, Hu G, Wei G, et al. c-Myc is a universal amplifier of expressed genes in lymphocytes and embryonic stem cells. Cell 2012;151:68-79. DOI PubMed PMC 
48. Brown JD, Lin CY, Duan Q, et al. NF- $\mathrm{kB}$ directs dynamic super enhancer formation in inflammation and atherogenesis. Mol Cell 2014;56:219-31. DOI PubMed PMC

49. Præstholm SM, Siersbæk MS, Nielsen R, et al. Multiple mechanisms regulate H3 acetylation of enhancers in response to thyroid hormone. PLoS Genet 2020;16:e1008770. DOI PubMed PMC

50. Cheng SY, Leonard JL, Davis PJ. Molecular aspects of thyroid hormone actions. Endocr Rev 2010;31:139-70. DOI PubMed PMC

51. Mullen AC, Orlando DA, Newman JJ, et al. Master transcription factors determine cell-type-specific responses to TGF- $\beta$ signaling. Cell 2011;147:565-76. DOI PubMed PMC

52. Trompouki E, Bowman TV, Lawton LN, et al. Lineage regulators direct BMP and Wnt pathways to cell-specific programs during differentiation and regeneration. Cell 2011;147:577-89. DOI PubMed PMC

53. Allen BL, Taatjes DJ. The Mediator complex: a central integrator of transcription. Nat Rev Mol Cell Biol 2015;16:155-66. DOI PubMed PMC

54. Barbieri CE, Baca SC, Lawrence MS, et al. Exome sequencing identifies recurrent SPOP, FOXA1 and MED12 mutations in prostate cancer. Nat Genet 2012;44:685-9. DOI PubMed PMC

55. Makinen N, Mehine M, Tolvanen J, et al. MED12, the mediator complex subunit 12 gene, is mutated at high frequency in uterine leiomyomas. Science 2011;334:252-5. DOI PubMed

56. Jones PA, Issa JP, Baylin S. Targeting the cancer epigenome for therapy. Nat Rev Genet 2016;17:630-41. DOI PubMed

57. Hnisz D, Day DS, Young RA. Insulated neighborhoods: structural and functional units of mammalian gene control. Cell 2016;167:1188-200. DOI PubMed PMC

58. Gorkin DU, Leung D, Ren B. The 3D genome in transcriptional regulation and pluripotency. Cell stem cell 2014;14:762-75. DOI PubMed PMC

59. Gibcus JH, Dekker J. The hierarchy of the 3D genome. Mol Cell 2013;49:773-82. DOI PubMed PMC

60. Phillips-Cremins JE, Corces VG. Chromatin insulators: linking genome organization to cellular function. Mol Cell 2013;50:461-74. DOI PubMed PMC

61. Lawrence MS, Stojanov P, Mermel CH, et al. Discovery and saturation analysis of cancer genes across 21 tumour types. Nature 2014;505:495-501. DOI PubMed PMC

62. Viny AD, Ott CJ, Spitzer B, et al. Dose-dependent role of the cohesin complex in normal and malignant hematopoiesis. J Cell Mol Med 2015;212:1819-32. DOI PubMed PMC

63. Drier Y, Cotton MJ, Williamson KE, et al. An oncogenic MYB feedback loop drives alternate cell fates in adenoid cystic carcinoma. Nat Genet 2016;48:265-72. DOI PubMed PMC

64. Tomazou EM, Sheffield NC, Schmidl C, et al. Epigenome mapping reveals distinct modes of gene regulation and widespread enhancer reprogramming by the oncogenic fusion protein EWS-FLI1. Cell Rep 2015;10:1082-95. DOI PubMed PMC

65. Zhang X, Choi PS, Francis JM, et al. Identification of focally amplified lineage-specific super-enhancers in human epithelial cancers. Nat Genet 2016;48:176-82. DOI PubMed PMC

66. Mansour MR, Abraham BJ, Anders L, et al. An oncogenic super-enhancer formed through somatic mutation of a noncoding intergenic element. Science 2014;346:1373-7. DOI PubMed PMC

67. Nabet B, Broin PÓ, Reyes JM, et al. Deregulation of the Ras-Erk signaling axis modulates the enhancer landscape. Cell Rep 2015;12:1300-13. DOI PubMed PMC

68. Katainen R, Dave K, Pitkänen E, et al. CTCF/cohesin-binding sites are frequently mutated in cancer. Nat Genet 2015;47:818-21. DOI PubMed

69. Esteller M. Epigenetics in cancer. N Engl J Med 2008;358:1148-59. DOI PubMed

70. Ando M, Saito Y, Xu G, et al. Chromatin dysregulation and DNA methylation at transcription start sites associated with transcriptional repression in cancers. Nat Commun 2019;10:2188. DOI PubMed PMC

71. Wang Z, Yin J, Zhou W, et al. Complex impact of DNA methylation on transcriptional dysregulation across 22 human cancer types. Nucleic Acids Res 2020;48:2287-302. DOI PubMed PMC

72. Baylin SB, Jones PA. Epigenetic determinants of cancer. Cold Spring Harb Perspect Biol 2016;8:a019505. DOI PubMed PMC

73. Polak P, Karlić R, Koren A, et al. Cell-of-origin chromatin organization shapes the mutational landscape of cancer. Nature 2015;518:360-4. DOI PubMed PMC

74. Ayob AZ, Ramasamy TS. Cancer stem cells as key drivers of tumour progression. J Biomed Sci 2018;25:20. DOI PubMed PMC

75. Batlle E, Clevers H. Cancer stem cells revisited. Nat Med 2017;23:1124-34. DOI PubMed

76. Greaves M, Maley CC. Clonal evolution in cancer. Nature 2012;481:306-13. DOI PubMed PMC

77. Loh YH, Wu Q, Chew JL, et al. The Oct4 and Nanog transcription network regulates pluripotency in mouse embryonic stem cells. Nat Genet 2006;38:431-40. DOI PubMed

78. Boyer LA, Lee TI, Cole MF, et al. Core transcriptional regulatory circuitry in human embryonic stem cells. Cell 2005;122:947-56. DOI PubMed PMC

79. Kagey MH, Newman JJ, Bilodeau S, et al. Mediator and cohesin connect gene expression and chromatin architecture. Nature 2010;467:430-5. DOI PubMed PMC

80. Rahl PB, Lin CY, Seila AC, et al. c-Myc regulates transcriptional pause release. Cell 2010;141:432-45. DOI PubMed PMC

81. Poli V, Fagnocchi L, Fasciani A, et al. MYC-driven epigenetic reprogramming favors the onset of tumorigenesis by inducing a stem cell-like state. Nat Commun 2018;9:1024. DOI PubMed PMC

82. Ben-Porath I, Thomson MW, Carey VJ, et al. An embryonic stem cell-like gene expression signature in poorly differentiated aggressive human tumors. Nat Genet 2008;40:499-507. DOI PubMed PMC 
83. Wong DJ, Liu H, Ridky TW, Cassarino D, Segal E, Chang HY. Module map of stem cell genes guides creation of epithelial cancer stem cells. Cell Stem Cell 2008;2:333-44. DOI PubMed PMC

84. Kim J, Woo AJ, Chu J, et al. A Myc network accounts for similarities between embryonic stem and cancer cell transcription programs. Cell 2010;143:313-24. DOI PubMed PMC

85. Efroni S, Duttagupta R, Cheng J, et al. Global transcription in pluripotent embryonic stem cells. Cell Stem Cell 2008;2:437-47. DOI PubMed PMC

86. Bernstein BE, Mikkelsen TS, Xie X, et al. A bivalent chromatin structure marks key developmental genes in embryonic stem cells. Cell 2006;125:315-26. DOI PubMed

87. Azuara V, Perry P, Sauer S, et al. Chromatin signatures of pluripotent cell lines. Nat Cell Biol 2006;8:532-8. DOI PubMed

88. Gan Q, Yoshida T, McDonald OG, Owens GK. Concise review: epigenetic mechanisms contribute to pluripotency and cell lineage determination of embryonic stem cells. Stem Cells 2007;25:2-9. DOI PubMed

89. Mikkelsen TS, Ku M, Jaffe DB, et al. Genome-wide maps of chromatin state in pluripotent and lineage-committed cells. Nature 2007;448:553-60. DOI PubMed PMC

90. Lee WK, Hwang S, Kim D, et al. Distinct features of nonthyroidal illness in critically ill patients with infectious diseases. Medicine (Baltimore) 2016;95:e3346. DOI PubMed PMC

91. Aranda A, Pascual A. Nuclear hormone receptors and gene expression. Physiol Rev 2001;81:1269-304. DOI PubMed

92. Méndez-Pertuz M, Sánchez-Pacheco A, Aranda A. The thyroid hormone receptor antagonizes CREB-mediated transcription. EMBO $J$ 2003;22:3102-12. DOI PubMed PMC

93. Rogatsky I, Zarember KA, Yamamoto KR. Factor recruitment and TIF2/GRIP1 corepressor activity at a collagenase-3 response element that mediates regulation by phorbol esters and hormones. EMBOJ 2001;20:6071-83. DOI PubMed PMC

94. Kim WG, Cheng SY. Thyroid hormone receptors and cancer. Biochim Biophys Acta 2013;1830:3928-36. DOI PubMed PMC

95. Li Z, Meng ZH, Chandrasekaran R, et al. Biallelic inactivation of the thyroid hormone receptor $\beta 1$ gene in early stage breast cancer. Cancer Res 2002;62:1939-43. PubMed

96. Iwasaki Y, Sunaga N, Tomizawa Y, et al. Epigenetic inactivation of the thyroid hormone receptor $\beta 1$ gene at 3p24. 2 in lung cancer. Ann Surg Oncol 2010;17:2222-8. DOI PubMed

97. Joseph B, Ji M, Liu D, Hou P, Xing M. Lack of mutations in the thyroid hormone receptor (TR) $\alpha$ and $\beta$ genes but frequent hypermethylation of the TR $\beta$ gene in differentiated thyroid tumors. J Clin Endocrinol Metab 2007;92:4766-70. DOI PubMed

98. Dunwell TL, Hesson LB, Pavlova TV, et al. Epigenetic analysis of childhood acute lymphoblastic leukemia. Epigenetics 2009;4:18593. DOI PubMed

99. Hörkkö TT, Tuppurainen K, George SM, Jernvall P, Karttunen TJ, Mäkinen MJ. Thyroid hormone receptor $\beta 1$ in normal colon and colorectal cancer-association with differentiation, polypoid growth type and K-ras mutations. Int J Cancer 2006;118:1653-9. DOI PubMed

100. Kim WG, Zhao L, Kim DW, Willingham MC, Cheng SY. Inhibition of tumorigenesis by the thyroid hormone receptor $\beta$ in xenograft models. Thyroid 2014;24:260-9. DOI PubMed PMC

101. Kim WG, Zhu X, Kim DW, Zhang L, Kebebew E, Cheng SY. Reactivation of the silenced thyroid hormone receptor $\beta$ gene expression delays thyroid tumor progression. Endocrinology 2013;154:25-35. DOI PubMed PMC

102. Jazdzewski K, Boguslawska J, Jendrzejewski J, et al. Thyroid hormone receptor $\beta$ (THRB) is a major target gene for microRNAs deregulated in papillary thyroid carcinoma (PTC). J Clin Endocrinol Metab 2011;96:E546-53. DOI PubMed PMC

103. Suzuki H, Willingham MC, Cheng SY. Mice with a mutation in the thyroid hormone receptor $\beta$ gene spontaneously develop thyroid carcinoma: a mouse model of thyroid carcinogenesis. Thyroid 2002;12:963-9. DOI PubMed

104. Guigon C, Kim D, Willingham M, Cheng S. Mutation of thyroid hormone receptor- $\beta$ in mice predisposes to the development of mammary tumors. Oncogene 2011;30:3381-90. DOI PubMed PMC

105. Furumoto H, Ying H, Chandramouli G, et al. An unliganded thyroid hormone $\beta$ receptor activates the cyclin D1/cyclin-dependent kinase/retinoblastoma/E2F pathway and induces pituitary tumorigenesis. Mol Cell Biol 2005;25:124-35. DOI PubMed PMC

106. Kato Y, Ying H, Willingham MC, Cheng SY. A tumor suppressor role for thyroid hormone $\beta$ receptor in a mouse model of thyroid carcinogenesis. Endocrinology 2004;145:4430-8. DOI PubMed

107. Zhu XG, Zhao L, Willingham MC, Cheng SY. Thyroid hormone receptors are tumor suppressors in a mouse model of metastatic follicular thyroid carcinoma. Oncogene 2010;29:1909-19. DOI PubMed PMC

108. Gabay M, Li Y, Felsher DW. MYC activation is a hallmark of cancer initiation and maintenance. Cold Spring Harb Perspect Med 2014;4:a014241. DOI PubMed PMC

109. Haugen D, Akslen L, Varhaug J, Lillehaug J. Demonstration of a TGF- $\alpha$-EGF-receptor autocrine loop and c-myc protein overexpression in papillary thyroid carcinomas. Int J Cancer 1993;55:37-43. DOI PubMed

110. Enomoto K, Zhu X, Park S, et al. Targeting MYC as a therapeutic intervention for anaplastic thyroid cancer. J Clin Endocrinol Metab 2017;102:2268-80. DOI PubMed PMC

111. Terrier P, Sheng Z, Schlumberger M, et al. Structure and expression of c-myc and c-fos proto-oncogenes in thyroid carcinomas. $\mathrm{Br} J$ Cancer 1988;57:43-7. DOI PubMed PMC

112. Romano M, Grattone M, Karner M, et al. Relationship between the level of c-myc mRNA and histologic aggressiveness in thyroid tumors. Horm Res Paediatr 1993;39:161-5. DOI PubMed

113. Zhu X, Zhao L, Park JW, Willingham MC, Cheng SY. Synergistic signaling of KRAS and thyroid hormone receptor $\beta$ mutants promotes undifferentiated thyroid cancer through MYC up-regulation. Neoplasia 2014;16:757-69. DOI PubMed PMC

114. Soucek L, Whitfield JR, Sodir NM, et al. Inhibition of Myc family proteins eradicates KRas-driven lung cancer in mice. Genes Dev 
2013;27:504-13. DOI PubMed PMC

115. Kouzarides T. Chromatin modifications and their function. Cell 2007;128:693-705. DOI PubMed

116. Filippakopoulos P, Picaud S, Mangos M, et al. Histone recognition and large-scale structural analysis of the human bromodomain family. Cell 2012;149:214-31. DOI PubMed PMC

117. Mertz JA, Conery AR, Bryant BM, et al. Targeting MYC dependence in cancer by inhibiting BET bromodomains. Proc Natl Acad Sci U S A 2011;108:16669-74. DOI PubMed PMC

118. Delmore JE, Issa GC, Lemieux ME, et al. BET bromodomain inhibition as a therapeutic strategy to target c-Myc. Cell 2011;146:90417. DOI PubMed PMC

119. Bian B, Bigonnet M, Gayet O, et al. Gene expression profiling of patient-derived pancreatic cancer xenografts predicts sensitivity to the BET bromodomain inhibitor JQ 1: implications for individualized medicine efforts. EMBO Mol Med 2017;9:482-97. DOI PubMed PMC

120. Li N, Yang L, Qi XK, et al. BET bromodomain inhibitor JQ1 preferentially suppresses EBV-positive nasopharyngeal carcinoma cells partially through repressing c-Myc. Cell Death Dis 2018;9:761. DOI PubMed PMC

121. Shao Q, Kannan A, Lin Z, Stack BC, Suen JY, Gao L. BET protein inhibitor JQ1 attenuates Myc-amplified MCC tumor growth in vivo. Cancer Res 2014;74:7090-102. DOI PubMed PMC

122. Baratta MG, Schinzel AC, Zwang Y, et al. An in-tumor genetic screen reveals that the BET bromodomain protein, BRD4, is a potential therapeutic target in ovarian carcinoma. Proc Natl Acad Sci U S A 2015;112:232-7. DOI PubMed PMC

123. Gao X, Wu X, Zhang X, et al. Inhibition of BRD4 suppresses tumor growth and enhances iodine uptake in thyroid cancer. Biochem Biophys Res Commun 2016;469:679-85. DOI PubMed

124. Mio C, Conzatti K, Baldan F, et al. BET bromodomain inhibitor JQ1 modulates microRNA expression in thyroid cancer cells. Oncol Rep 2018;39:582-8. DOI PubMed

125. Zhu X, Enomoto K, Zhao L, et al. Bromodomain and extraterminal protein inhibitor JQ1 suppresses thyroid tumor growth in a mouse model. Clin Cancer Res 2017;23:430-40. DOI PubMed PMC

126. McFadden DG, Vernon A, Santiago PM, et al. p53 constrains progression to anaplastic thyroid carcinoma in a Braf-mutant mouse model of papillary thyroid cancer. Proc Natl Acad Sci U S A 2014;111:E1600-9. DOI PubMed PMC

127. Zaballos MA, Santisteban P. Key signaling pathways in thyroid cancer. J Endocrinol 2017;235:R43-61. DOI PubMed

128. Naoum GE, Morkos M, Kim B, Arafat W. Novel targeted therapies and immunotherapy for advanced thyroid cancers. Mol Cancer 2018;17:51. DOI PubMed PMC

129. Zhu X, Holmsen E, Park S, Willingham MC, Qi J, Cheng SY. Synergistic effects of BET and MEK inhibitors promote regression of anaplastic thyroid tumors. Oncotarget 2018;9:35408-21. DOI PubMed PMC

130. Ozer HG, El-Gamal D, Powell B, et al. BRD4 profiling identifies critical chronic lymphocytic leukemia oncogenic circuits and reveals sensitivity to PLX51107, a novel structurally distinct BET inhibitor. Cancer Discov 2018;8:458-77. DOI PubMed PMC

131. Barrett SD, Bridges AJ, Dudley DT, et al. The discovery of the benzhydroxamate MEK inhibitors CI-1040 and PD 0325901. Bioorg Med Chem Lett 2008;18:6501-4. DOI PubMed

132. Wang L, Lonard DM, O'Malley BW. The role of steroid receptor coactivators in hormone dependent cancers and their potential as therapeutic targets. Horm Cancer 2016;7:229-35. DOI PubMed PMC

133. Yao TP, Ku G, Zhou N, Scully R, Livingston DM. The nuclear hormone receptor coactivator SRC-1 is a specific target of p300. Proc Natl Acad Sci U S A 1996;93:10626-31. DOI PubMed PMC

134. Anafi M, Yang YF, Barlev NA, et al. GCN5 and ADA adaptor proteins regulate triiodothyronine/GRIP1 and SRC-1 coactivatordependent gene activation by the human thyroid hormone receptor. Mol Endocrinol 2000;14:718-32. DOI PubMed

135. Brown K, Chen Y, Underhill TM, Mymryk JS, Torchia J. The coactivator p/CIP/SRC-3 facilitates retinoic acid receptor signaling via recruitment of GCN5. J Biol Chem 2003;278:39402-12. DOI PubMed

136. Koh SS, Chen D, Lee YH, Stallcup MR. Synergistic enhancement of nuclear receptor function by p160 coactivators and two coactivators with protein methyltransferase activities. J Biol Chem 2001;276:1089-98. DOI PubMed

137. Spencer TE, Jenster G, Burcin MM, et al. Steroid receptor coactivator-1 is a histone acetyltransferase. Nature 1997;389:194-8. DOI PubMed

138. Zhang H, Yi X, Sun X, et al. Differential gene regulation by the SRC family of coactivators. Genes Dev 2004;18:1753-65. DOI PubMed PMC

139. Anzick SL, Kononen J, Walker RL, et al. AIB1, a steroid receptor coactivator amplified in breast and ovarian cancer. Science 1997;277:965-8. DOI PubMed

140. Yan J, Tsai SY, Tsai MJ. SRC-3/AIB1: transcriptional coactivator in oncogenesis. Acta Pharmacol Sin 2006;27:387-94. DOI PubMed

141. Xu J, Wu RC, O'Malley BW. Normal and cancer-related functions of the p160 steroid receptor co-activator (SRC) family. Nat Rev Cancer 2009;9:615-30. DOI PubMed PMC

142. Torres-Arzayus MI, Font de Mora J, Yuan J, et al. High tumor incidence and activation of the PI3K/AKT pathway in transgenic mice define AIB1 as an oncogene. Cancer Cell 2004;6:263-74. DOI PubMed

143. Ying H, Willingham $\mathrm{M}$, Cheng $\mathrm{S}$. The steroid receptor coactivator-3 is a tumor promoter in a mouse model of thyroid cancer. Oncogene 2008;27:823-30. DOI PubMed

144. Lonard DM, O'malley BW. Nuclear receptor coregulators: modulators of pathology and therapeutic targets. Nat Rev Endocrinol 2012;8:598-604. DOI PubMed PMC

145. Song X, Chen J, Zhao M, et al. Development of potent small-molecule inhibitors to drug the undruggable steroid receptor 
coactivator-3. Proc Natl Acad Sci U S A 2016;113:4970-5. DOI PubMed PMC

146. Landa I, Ibrahimpasic T, Boucai L, et al. Genomic and transcriptomic hallmarks of poorly differentiated and anaplastic thyroid cancers. J Clin Invest 2016;126:1052-66. DOI PubMed PMC

147. Lee WK, Kim WG, Fozzatti L, et al. Steroid receptor coactivator-3 as a target for anaplastic thyroid cancer. Endocr Relat Cancer 2020;27:209-20. DOI PubMed PMC

148. Lee HJ, Lee WK, Kang CW, Ku CR, Cho YH, Lee EJ. A selective cyclin-dependent kinase 4, 6 dual inhibitor, Ribociclib (LEE011) inhibits cell proliferation and induces apoptosis in aggressive thyroid cancer. Cancer Lett 2018;417:131-40. DOI PubMed

149. Rader J, Russell MR, Hart LS, et al. Dual CDK4/CDK6 inhibition induces cell-cycle arrest and senescence in neuroblastoma. Clin Cancer Res 2013;19:6173-82. DOI PubMed PMC

150. Zhang YX, Sicinska E, Czaplinski JT, et al. Antiproliferative effects of CDK4/6 inhibition in CDK4-amplified human liposarcoma in vitro and in vivo. Mol Cancer Ther 2014;13:2184-93. DOI PubMed

151. Finn RS, Martin M, Rugo HS, et al. Palbociclib and letrozole in advanced breast cancer. N Engl J Med 2016;375:1925-36. DOI PubMed

152. Hortobagyi GN, Stemmer SM, Burris HA, et al. Ribociclib as first-line therapy for HR-positive, advanced breast cancer. $N$ Engl $J$ Med 2016;375:1738-48. DOI PubMed

153. Valenciaga A, Saji M, Yu L, et al. Transcriptional targeting of oncogene addiction in medullary thyroid cancer. JCI Insight 2018;3:e122225. DOI PubMed PMC

154. Geng M, Yang Y, Cao X, Dang L, Zhang T, Zhang L. Targeting CDK12-mediated transcription regulation in anaplastic thyroid carcinoma. Biochem Biophys Res Commun 2019;520:544-50. DOI PubMed

155. Zhu X, Park S, Lee WK, Cheng SY. Potentiated anti-tumor effects of BETi by MEKi in anaplastic thyroid cancer. Endocr Relat Cancer 2019;26:739-50. DOI PubMed PMC

156. Chipumuro E, Marco E, Christensen CL, et al. CDK7 inhibition suppresses super-enhancer-linked oncogenic transcription in MYCNdriven cancer. Cell 2014;159:1126-39. DOI PubMed PMC 